\title{
Meninas violando a lei: uma discussão das políticas e das medidas socioeducativas no Brasil \\ (Girls Violating the Law: A Discussion of Socio-Educational Policies and Measures in Brazil)
}

OÑATI SOCIO-LEGAL SERIES, VOLUME 10, ISSUE 2 (2020), 291-312: El GÉNERO DE LOS SISTEMAS PENALES JUVENILES: DEBATES NECESARIOS

DOI LINK: HTTPS://DOI.ORG/10.35295/OSLS.IISL/0000-0000-0000-1073

RECEIVED 27 FEBRUARY 2019, ACCEPTED 02 SEPTEMBER 2019

\author{
ANDREA CRISTINA COELHO SCISLESKI* (i) \\ GIOVANA BARBIERI GALEANO* (D)
}

\section{Resuimo}

Este artigo se origina de uma pesquisa que problematiza as políticas públicas direcionadas à juventude que comete atos infracionais, especialmente as adolescentes mulheres. Norteadas pelo pensamento de Michel Foucault, discutimos e analisamos o modo como o discurso sobre a população jovem em conflito com a lei é operacionalizado para legitimar intervenções no meio socioeducativo. Partimos da arqueogenealogia foucaultiana para pensar o presente nas relações de poder-saber, refletindo acerca dos discursos sobre os direitos das jovens que cumprem medidas socioeducativas, pois as políticas da socioeducação têm sido pensada, prioritariamente, para os jovens do sexo masculino, invisibilizando as condições específicas que implicam a entrada das adolescentes no sistema de justiça. A operacionalização das políticas públicas para a juventude em conflito com a lei, no presente, indica a execução de medidas que, subsidiadas por discursos produzidos na relação entre instituições de saúde e justiça, violam os direitos garantidos em lei.

\section{Palavras-chave}

Criminologia; meninas infratoras; sistema socioeducativo; políticas públicas brasileiras; resistência

\footnotetext{
* Doutora em Psicologia- 2010 (Pontificia Universidade Catolica do Rio Grande do Sul), Mestre em Psicologia Social e Institucional - 2006 (Universidade Federal do Rio Grande do Sul), Graduaçao em Psicologia - 2004 (Universidade Federal do Rio Grande do Sul). È pesquisadora convidada do grupo Epolitcs do Instituto de Psicologia da Universidade Federal do Rio Grande do Sul/Brasil. Email: andrea.scisleski@gmail.com

* Doutoranda em Psicologia Social e Institucional, Universidade Federal do Rio Grande do Sul; Mestre em Psicologia - 2017, Universidade Catolica Dom Bosco; Graduaçao em Psicologia 2015 - Universidade Catolica Dom Bosco. Email: giovanagaleano@hotmail.com
} 


\section{Abstract}

This article is the result of a research that problematizes the public policies directed to the youth that commits offensive conducts, especially the adolescent women. Guided by Michel Foucault's thought, we discuss and analyze how the discourse on the young population in conflict with the law is operationalized to legitimize interventions in the socio-educational environment. We started from the Foucauldian archaeogenealogy to think about the present in power-knowledge relations, reflecting on the discourses on the rights of young women who serve socio-educational measures, because the policies of socio-education have been designed for young men, invisibilizing the specific conditions that imply the entry of girls into the Brazilian justice system. The operationalization of public policies for youth in conflict with the law, in the present, indicates the implementation of measures that, subsidized by speeches produced in the relationship between health institutions and justice, violate the rights guaranteed by law.

\section{Key words}

Criminology; offending girls; socio-educational system; Brazilian public policies; resistance

\section{Resumen}

Este artículo se origina en una investigación que problematiza las políticas públicas dirigidas a jóvenes que cometen infracciones, especialmente a las adolescentes. Guiadas por el pensamiento de Michel Foucault, discutimos y analizamos cómo se operacionaliza el discurso sobre la población joven en conflicto con la ley para legitimar las intervenciones en el entorno socioeducativo. Partimos de la arqueogenealogía de Foucault para recapacitar sobre el presente en las relaciones de poder-conocimiento, reflexionando acerca de los discursos sobre los derechos de los y las jóvenes que cumplen con las medidas socioeducativas, ya que las políticas de educación social se han diseñado principalmente para hombres jóvenes, haciendo invisibles las condiciones que implican la entrada de los adolescentes a la justicia. La operacionalización de las políticas públicas para jóvenes en conflicto con la ley, en la actualidad, indica la implementación de medidas que, subsidiadas por discursos producidos en la relación entre instituciones de salud y justicia, violan los derechos garantizados por la ley.

\section{Palabras clave}

Criminología; mujeres jóvenes infractoras; sistema socioeducativo; políticas públicas en Brasil; resistencia 


\section{Índice / Table of contents}

1. Introdução 294

2. Políticas para infância e juventude: dos expostos à violação de direitos e o aparecimento do gênero feminino

2.1. Jovens mulheres e ato infracional no contexto da

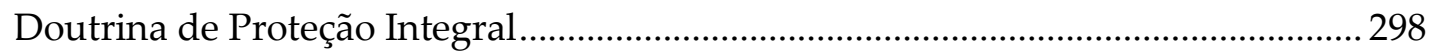

3. Medida Socioeducativa em Meio Aberto: rede pessoal e projeto de vida ................... 302

3.1. No império da lei quem tem projeto de vida é sujeito de direito ........................304

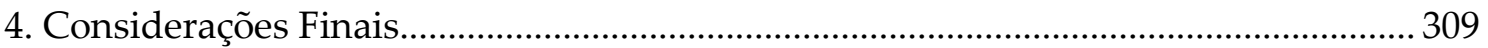

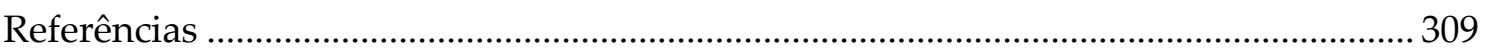

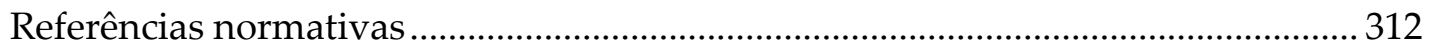




\section{Introdução}

No Brasil a questão do ato infracional e, consequentemente, a organização do campo das políticas públicas para a juventude em conflito com a lei, tem sido analisada tendo como foco a infração de jovens do sexo masculino, invisibilizando, não raro, as condições específicas que implicam a entrada de jovens do sexo feminino no sistema de justiça. Neste trabalho, buscaremos debater, enfatizando dois eixos para análise: primeiro, a discussão da invisibilidade das jovens no sistema socioeducativo, e segundo, a condução geral das políticas de atendimento no sistema socioeducativo. Dessa maneira, através de revisão de literatura e visitas realizadas a estabelecimentos relacionados às medidas socioeducativas, objetivamos apresentar, no caso do Brasil, o seguinte desdobramento: a) discussões sobre as questões de gênero presentes no cometimento do ato infracional por jovens mulheres, que geralmente se associam à submissão a um homem; b) problematizar a política de drogas em relação à entrada dessas jovens no campo da infração; c) o modo como têm sido operacionalizadas práticas em relação à população juvenil em conflito com a lei no cumprimento da medida socioeducativa; d) apontar para uma proposta de uma política de pesquisa que tenha como foco não apenas a problematização do social, mas, especialmente, os próprios efeitos de sua produção de conhecimento.

Diante disso, este artigo objetiva problematizar as intervenções direcionadas à vida da juventude em conflito com a lei, a partir do que encontramos em documentos elaborados para contribuir com a formação de operadores e gestores do sistema socioeducativo no Brasil e as práticas operacionalizadas em estabelecimentos da política pública de Assistência Social que atende a juventude que cumpre medida socioeducativa em meio aberto. Buscamos analisar, norteadas pelos pensamentos de Michel Foucault e Giorgio Agamben, o modo como o discurso sobre a população jovem que comete infrações é operacionalizada no cumprimento das medidas socioeducativas. O discurso (Foucault 1996, 2008b) não é tomado como uma unidade linguística, mas enquanto o arranjo de poder e saber cujo efeito é a produção de verdade e, no caso da juventude foco deste texto, a objetivação de uma população criminosa e perigosa atrelada ao estereótipo da mulher e situação de submissão com relação ao parceiro que emerge no que diz respeito ao cometimento de delito por jovens mulheres.

Inicialmente é pertinente definir o método como um dispositivo que possibilita visibilizar o arranjo das relações de poder e saber (Foucault 1979), compreendidas como as relações dos sujeitos entre si, bem como dos sujeitos e as instituições, que tem como efeito a produção de práticas e saberes voltadas às intervenções direcionadas à vida. Desse modo, a arqueogenealogia foucaultiana possibilita dar visibilidade às relações de poder e às produções de saber, sem qualquer pretensão de uma busca por origem da verdade ou de uma continuidade histórica, mas para refletir acerca dos discursos sobre os direitos dos jovens em cumprimento de medida socioeducativa (Foucault 1979, Silva 2004, Agamben 2009, Trevisani 2013).

Para esta escrita, cabe mencionar que os procedimentos metodológicos da investigação se constituíram pela análise das práticas que incidem sobre a jovem, bem como de documentos que ofertam diretrizes para conduzir essas práticas. Dessa forma, nos valemos da análise de documentos e visitas a um Centro de Referência Especializado de Assistência Social - CREAS (que atende jovens de ambos os sexos) e Unidade 
Educacional de Internação - UNEI Feminina durante os anos de 2012 a 2017, na cidade de Campo Grande - Mato Grosso do Sul/Brasil, para a composição metodológica da pesquisa. Os documentos dizem respeito ao relatório do Conselho Nacional de Justiça (2015) sobre as medidas socioeducativas de internação das jovens do sexo feminino no Brasil; o relatorio da Ordem dos Adovgados do Brasil em visita a uma Unidade de Internação do estado do Mato Grosso do Sul, e a análise de três guias distribuídos no ano de 2006 pela Secretaria Especial dos Direitos Humanos da Presidência da República (Secretaria Especial dos Direitos Humanos 2006a, 2006b, 2006c) - que mesmo com a implementação da lei que institui o Sistema Nacional de Atendimento Socioeducativo SINASE (Lei $n^{\circ}$ 12.594) regulamentando a execução das medidas socioeducativas servem como diretrizes fundamentadoras das práticas dos técnicos que atuam com a juventude em cumprimento de medidas socioeducativas.

É importante ter presente que esta não é apenas uma discussão jurídica, mas também uma forma de governar e intervir que se dirige à vida dos adolescentes em conflito com a lei, destacando aqui a das mulheres adolescentes (Foucault 2008). Assim, continuaremos apontando, ao longo do texto, como a vida das adolescentes em conflito com a lei tem sido governada no atual contexto brasileiro.

\section{Políticas para infância e juventude: dos expostos à violação de direitos e o aparecimento do gênero feminino}

As ações direcionadas para a juventude no âmbito socioeducativo constituem formas de gestão dessa categoria. Ou seja, tais ações não se organizam apenas em nível jurídico, procedimentos vinculados à infração, mas enquanto intervenções direcionadas à vida. Nesse sentido, podemos pensar de acordo com Foucault (1988), que desde a criação do Estado-Nação e com a consequente emergência da população como um problema de governo, as intervenções produzidas e direcionadas à população incidiram, tanto em nível individual quanto coletivo, sobre a vida dos sujeitos. A esse poder que intervém na vida, na perspectiva foucaultiana, (Foucault 1988, 2008a, 2008b) denominou-se biopoder. O objetivo dessas intervenções é o governo a partir do esquadrinhamento, descrição e definição dos fenômenos referentes à população, para que assim seja possível direcionar estratégias de governo em função de uma determinada racionalidade (Foucault 2005).

Vale ressaltar que o governo no pensamento foucaultiano é compreendido como cálculo estratégico de intervenção e implica a constituição da população não somente como um problema, mas, principalmente, objeto de saber. Essa produção de saber se constitui tanto em termos demográficos quanto socioeconômicos. Isto é, deve-se conhecer, contabilizar, identificar as regiões e as características dos habitantes de um território e, com isso, desenvolver as estratégias de intervenção, tais como a criação de políticas públicas direcionadas a categorias populacionais específicas.

Os processos de investimento são aqueles referentes à criação de condições que possibilitem o fomento da vida como, por exemplo, as condições de saúde, moradia, alimentação, segurança, dentre outros. A população é, enquanto conjunto heterogêneo, pensada em categorias, o que possibilita a eficácia dos mecanismos de governo. Ou seja, há um esquadrinhamento efetuado no corpo populacional para o qual serão direcionadas tecnologias de acordo com as especificidades de cada uma das 
subcategorias forjadas, para melhor aplicação e gestão dos pressupostos da racionalidade vigente. A essa maneira como se conduz a conduta dos homens, investindo e fomentando a vida, a partir de subcategorias, Michel Foucault denominou de governamentalidade (Foucault 1979).

Pensar a categoria populacional da juventude em conflito com a lei, no contexto brasileiro implica, primeiramente, compreender que as lógicas de governo da infância e juventude nem sempre se constituíram pelo investimento visando o fomento da vida. Além disso, é necessário situar o contexto social no qual as lógicas de governar a infância e juventude se desenvolveram e modularam o modo como as intervenções foram legitimadas junto à essa população em específico. Será, portanto, apenas em um contexto democrático que a criança e o adolescente terão afirmados em lei os direitos fundamentais à saúde, alimentação, educação, esporte, convívio familiar e comunitário, sendo "dever da família, da comunidade, da sociedade em geral e do poder público assegurar, com absoluta prioridade, a efetivação dos direitos" (Lei no 8.069). No entanto, a atual legislação em vigor dirigida às crianças e aos adolescentes no Brasil - Estatuto da Criança e do Adolescente - ECA, desde sua criação, tem sido amplamente criticada e combatida por correntes reacionárias do campo jurídico, apoiada por vários atores sociais, que a entendem como indulgente com a população infantil e juvenil. Essa perpectiva de conceber a legislação tem, muitas vezes, impedido sua efetivação na pratica cotidiana junto à população. No Brasil, esses discursos têm avançado com o objetivo de reduzir a idade da maioridade, especialmente com a nova configuração política instituída na presidência da república.

Retomando as legislações anteriores no contexto brasileiro a respeito da população infanto-juvenil, em 1927, através do Decreto no 17.943-A de 12 de outubro consolidaramse as leis de assistência e proteção a menores, conhecido como Código de Menores. Esse Decreto dispunha que o atendimento ao menor de dezoito anos seria direcionado pelas autoridades competentes caso o mesmo estivesse abandonado ou delinquisse (Decreto $n^{\text {o }}$ 17.943) e não distingue os sujeitos com relação ao gênero. Cabe explicar aqui que por autoridade competente compreende-se as instituições da justiça, da assistência, da polícia e, ainda, “autoridade pública" (Decreto n⿳0 17.943).

Ainda quanto ao referido decreto, é pertinente explicar que o abandono é apenas descrito como aquela ação praticada pela família de origem da criança, referindo-se, portanto, a quando os responsáveis entregam o menor para criação por terceiros, sejam essas outras famílias ou "as instituições destinadas a recolher e crear expostos" (Decreto no 17.943). Os expostos referiam-se à denominação dada às crianças com idade até sete anos que estavam abandonados. O termo vem da Roda dos Expostos, que era utilizada para rejeitar - ou expor - crianças. No contexto do Código de Menores em 1927, o "systema das rodas" foi substituído pela consignação direta das crianças à assistência, como podese ler nos artigos 17 e 18:

Art. 17. Os recolhimentos de expostos, salvo nos casos previstos pelo artigo seguinte, não podem receber creança sem a exhibição do registro civil de nascimento e a declaração de todas as circumstancias que poderão servir para identifical a; e deverão fazer a descripção dos signaes particulares e dos objectos encontrados no infante ou junto deste. Art. 18. Si é a mãe que apresenta o infante, ella não é adstricta a se dar a conhecer, nem a assignar o processo de entrega. Si, porém, ella espontaneamente fizer declaração do seu estado civil, que qualquer outra que esclareça a situação da creança, 
taes declarações serão recebidas e registradas pelo funcionario do recolhimento. (Decreto no 17.943 )

No que diz respeito à delinquência, os menores de quatorze anos eram considerados inimputáveis, sendo submetidos a um exame do estado "physico, mental e moral" e encaminhados à autoridade competente. Estabelece-se, no caso de crime cometido por maior de dezesseis e menor de dezoito anos que o mesmo cumprirá pena em estabelecimento para "condenados de menor idade, ou, em falta deste, a uma prisão commum com separação dos condemnados adultos" (Decreto no 17.943). A mulher, contudo, nesse documento jurídico aparece somente em dois momentos, quais sejam: no capítulo IX sobre o trabalho de menores, especificamente no art. 112 onde podemos ler que “Nenhum varão menor de 14 anos, nem mulher solteira menor de 18 anos, poderá exercer occupação alguma que se desempenho nas ruas, praças ou logares públicos; sob pena de ser apprehendido e julgado abandonado, e imposta ao seu responsável legal 50\$ a $500 \$$ de multa e dez a trinta dias de prisão cellular" (Decreto no 17.943). E no parágrafo $3^{\text {o }}$ do art. 132 sobre os crimes e contravenções, onde lemos que "Quando o crime recaia sobre infante ainda não inscripto no registro civil, e dentro do prazo legal da inscripção, para salvar a honra propria ou da mulher ou da mãe, da descendente, da filha adoptiva ou irmã, a pena é diminuida de um terço a um sexto" (Decreto $\mathrm{n}^{\circ}$ 17.943). Tais elementos apontam, assim, para esse processo de invisibilização da mulher não apenas a um parceiro, mas, fundamentalmente, à figura e tutela patriarcal.

Posteriormente, em 1979, instaura-se o novo Código de Menores que dispõe sobre "assistência, proteção e vigilância a menores" (Lei no 6.697). Nesse contexto, produzemse medidas de caráter preventivo, instituindo-se a Doutrina da Situação Irregular, isso acarretou que todos os menores que se encontrassem privados de "condições essenciais à sua subsistência, saúde e instrução obrigatória" sendo por "falta, ação ou omissão dos pais ou responsáveis" ou, ainda, "com desvio de conduta, em virtude de grave inadaptação familiar ou comunitária" e "autor de infração penal" seriam alvo de intervenções por parte do Estado (Lei no 6.697). Acrescenta-se que, nesse dispositivo legal, as questões relacionadas à criança e à juventude não dão visibilidade às diferenças de gênero, excetuando-se os momentos em que se trata da definição das responsabilidades do pai, mãe e responsáveis, tendo como foco, portanto, a família.

Com o Código de Menores de 1979, temos uma modificação em relação ao Decreto de 1927 (Decreto n⿳o 17.943), referente ao surgimento de uma intervenção que tem caráter preventivo, onde "as medidas de caráter preventivo aplicam-se a todo menor de dezoito anos, independentemente de sua situação" (Lei no 6.697). O Estado, contudo, ainda marca a presença de uma lógica menorista e tutelar, constituindo-se como a instância que intervirá em caso da falta da família ou responsável. Atrela-se, em ambos os Códigos, a conduta infracional à lei como efeito de uma perversão, desvio moral e inadaptação tanto da família de origem quanto do menor (Decreto $\mathrm{n}^{\mathrm{o}} 17.943$, Lei $\mathrm{n}^{\mathrm{o}}$ 6.697). Enfatizamos aqui que ainda enfrentamos uma condenação que se refere menos ao ato infracional cometido pela adolescente do que à imoralidade que a própria adolescente constitui para a sociedade, seja pela sua vinculação com parceiros que também cometeram alguma infração e que as impelem ao cometimento de ato infracional como veremos mais a frente no presente texto, seja pela responsabilidade atrelada à mulher de reconhecer os riscos nos quais incorre ao infringir a lei. Demandase, assim, da jovem não apenas um comportamento segundo o cumprimento da lei, mas, 
fundamentalmente, uma condução de sua vida que se funda no fato de ser mulher e "dar-se ao respeito".

Além disso, cabe destacar que a ideia de "família desestruturada" que aborda o Código de Menores de 1979 denuncia diretamente a configuração da sociedade patriarcal que subjazia naquele momento no cenário brasilieiro. Ou seja, a falta da figura paterna na concepção de uma susposta ideal configuração familiar não apenas invisibilizou (e ainda invisibiliza) o esforço de muitas mães solteiras que administravam suas famílias com seus filhos, como também indica uma função praticamente salvadora da presença do homem na gestão familiar. Dito de outro modo, essa ideia de falência familiar, que ainda hoje reverbera em muitos documentos legais e mesmo no exercicio cotidiano das práticas juridicas, ainda que sejam contrárias à própria legislação atual em vigor - o ECA -, entendem que a falta de estrutura familiar de onde essas adolescentes provêm é muitas vezes atribuída à ausência da figura paterna ou à má gestão materna da família (Caetano et al. 2019). Isto é - seja pela ausência do pai ou incompetência da mãe - percebemos a prevalência da lógica patriarcal, já que a figura paterna poderia ter sido uma resposta redentora à vida dessas jovens, enquanto a figura materna tem se demonstrado ineficaz.

\subsection{Jovens mulheres e ato infracional no contexto da Doutrina de Proteção Integral}

Atualmente, mesmo com toda modificação em termos de direitos, com a promulgação do Estatuto da Criança e do Adolescente (Lei no 8.069 - ECA -), muitos estudos (Vicentin 2005, Scisleski 2006, Scisleski et al. 2014, 2015b, 2017, Caetano et al. 2019) sobre a infância e juventude têm apontado a preponderância de práticas tutelares, punitivas e repressoras como as presentes nos antigos Códigos de Menores de 1927 e 1979 (Secretaria Especial dos Direitos Humanos 2006b), não apenas na operacionalização das medidas socioeducativas, mas, sobretudo, anteriormente ao cometimento do ato infracional, como é o caso da ausência de condições básicas de saúde, acesso à educação, segurança e moradia, dentre outros.

No que diz respeito às questões de gênero presentes no Estatuto, estas aparecem sumariamente associadas à função materna da mulher, especialmente no que diz respeito à atenção à saúde e acesso aos programas de planejamento reprodutivo, serviços de saúde destinados à gestante, garantia de escolha pelo tipo de parto pela mulher, garantia de acesso à rede primária de atendimento - unidades básicas de saúde - além de outros serviços à mulher e seus recém-nascidos. Destacamos, nesse âmbito, o parágrafo $10^{\circ}$ do art. $8^{\circ}$ sobre o direito à vida e à saúde que establece:

Incumbe ao poder público garantir, à gestante e à mulher com filho na primeira infância que se encontrem sob custódia em unidade de privação de liberdade, ambiência que atenda às normas sanitárias e assistenciais do Sistema Único de Saúde para o acolhimento do filho, em articulação com o sistema de ensino competente, visando ao desenvolvimento integral da criança. (Lei no ${ }^{8}$.069)

Temos, nesse contexto, um ponto complexo que diz respeito ao direito da mãe em cumprimento de medida estar acompanhada de seu filho ou filha. Ainda que se trate de um direito que visa garantir a ambos (mãe e criança) a condição de proximidade, cabe questionar as condições nas quais esse direito se efetiva, visto que a criança passaria a viver, também, em regime de internação. O relatório do Conselho Nacional de Justiça (2015) aponta que algumas regiões do país permitem a saída da jovem pelo período de 
amamentação da criança e que, posteriormente, deve retornar ao cumprimento da medida de internação. Vemos, então, que os cuidados direcionados à jovem se destinam tão somente àqueles referentes à saúde da mulher enquanto corpo grávido ou que amamente, e que a efetivação do direito de permanecer junto a sua (seu) filha (o) depende de um jogo de sorte no sentido de a jovem viver em uma região onde esse direito seja viabilizado. Dessa forma, podemos sintetizar que a figura feminina emerge no ECA reduzida à função materna das jovens.

O perfil das jovens mulheres em cumprimento de medida socioeducativa de internação se constitui por média de idade entre 15 e 17 anos no período de cometimento do ato infracional, as informações sobre cor/raça/etnia não estavam presentes em praticamente nenhum dos processo e Planos Individuais de Atendimento que foram avaliados e apresentados no relatório feito pelo Conselho Nacional de Justiça (2015, p. 23). O mesmo relatório aponta que a defasagem escolar também é presente na população feminina cujo “percentual considerável delas que estavam entre o $1^{\circ}$ e o $5^{\circ}$, mas a maioria, em todos os estados, cursava entre o 6o e o 9o ano" (Conselho Nacional de Justiça 2015, p. 26), situação que tem continuidade durante o período do cumprimento da medida, visto que não foi possível verificar a frequência escolar. No que diz respeito ao estado civil, temos que

a grande maioria das adolescentes é oficialmente solteira, mas muitas têm relacionamentos afetivos com companheiros com quem já dividem, inclusive, moradia. Essa hipótese é ainda mais procedente com número de adolescentes que possuem filhos: $37,5 \%$ sim, 59,4\% não (3,1\%) não informado. Das adolescentes que têm filhos, a faixa etária varia entre 0 a 1 ano (50\%) e de 1 a 3 anos (50\%), tendo alguns nascidos na unidade de internação. (Conselho Nacional de Justiça 2015, p. 25)

Retomando as questões sobre a saúde, algumas práticas desenvolvidas junto às jovens que cumprem medida socioeducativa de internação dizem respeito aos dias de beleza ou, ainda, chamados de "dias de princesa". Essas estratégias são desenvolvidas tendo como justificativa um cuidado com a autoestima das internas e, não raro, são "moeda de troca" com relação ao bom comportamento dentro do estabelecimento de internação. Isto é, caso a jovem cumpra as atividades que se destinam a ela, seja disciplinada, obediente e não entre em conflito com as demais internas ou funcionários da instituição, a ela é assegurado o "direito" de participar das atividades de beleza que acontecem em dias como dia da mulher, dia das mães, dentre outras datas comemorativas. Ao contrário, caso a jovem apresente comportamento indisciplinado em relação às regras da instituição, há uma "punição disciplinar" impedindo que a mesma participe das atividades. Temos, assim, uma dupla punição: 1. A própria internação; 2. As punições arbitrárias instituídas pelos estabelecimentos de internação. Cabe ressaltar ainda que na maioria dessas unidades a própria limpeza do local é realizada pelas jovens internadas. No entanto, é fundamental salientar que tanto a atividade de limpeza das unidades como o "dia da princesa" são práticas atribuídas sobretudo, numa lógica social patriarcal, ao gênero feminino.

No que diz respeito ao ato infracional, dados do Conselho Nacional de Justiça (2015) apontam que "os atos infracionais mais comuns no histórico infracional das adolescentes são o roubo (54\%) e o tráfico de drogas (33\%), seguido, por último, do porte ilegal de arma de fogo" (Conselho Nacional de Justiça 2015, p. 31). Cabe mencionar que a internação por drogas é sucedida pelo uso das mesmas, além disso, as jovens não são as primeiras da família a serem ou estarem presas, visto que "muitas delas relatam já ter 
familiares, amigos/as ou companheiros(as)/namorados (as) selecionados pelo Sistema de Justiça Criminal ou pelo sistema socioeducativo. As meninas não costumam ser a primeira "queda" no sistema de controle" (Conselho Nacional de Justiça 2015, p. 38). É interessante ressaltar que geralmente os crimes, precedidos pelos atos infracionais das meninas na família, foram cometidos por homens (pais, irmãos ou parceiros).

Ainda em relação à droga é importante destacar que o delito que se vincula ao tráfico de drogas está atrelado, por um lado, a um envolvimento vinculado ao parceiro e amigos onde está presente a dependência química e, por outro lado, como forma de alcançar uma certa independência financeira e sustento. Contudo, alguns estudos indicam que as adolescentes tendem a afirmar que estão ligadas ao crime pela sua relação com os seus parceiros e familiares do sexo masculino (Athayde et al. 2005, Scisleski 2006, Cunda e Silva 2014), como é o caso do tráfico de drogas, especialmente porque este crime está mais relacionado com uma relação comercial do que com atos que exigem o uso da força e da violência. Neste último aspecto, essas pesquisas têm questionado se o próprio crime e a forma como essas jovens mulheres estão ligadas a ele está subjacente a uma relação de submissão do gênero feminino ao masculino, reproduzindo a lógica patriarcal da sociedade.

Ressaltamos que o tráfico de drogas se apresenta, ainda, como uma forma não violenta com o âmbito da infração, visto que "a motivação parece ser pelo fato de ser um tipo de infração que não requer uso de violência" (Conselho Nacional de Justiça 2015, p. 29). Ademais, apresenta-se a questão de que, diferentemente do que se visibiliza com os jovens do sexo masculino, no caso das jovens mulheres "a prática do ato não resulta da personalidade violenta dessas adolescentes, mas de circunstâncias externas que se fossem diferentes, melhores, elas provavelmente não teriam transgredido a lei" e mais "uma das grandes dificuldades apontadas por eles, para a ressocialização das internas, é o fato de, após o cumprimento da medida, elas voltarem para a mesma situação anterior, ou seja, para contextos sociais vulneráveis" (Conselho Nacional de Justiça 2015, p. 194).

Outro paralelo a ser realizado com relação à internação de jovens do sexo masculino diz respeito à visita íntima. O relatório do Conselho Nacional de Justiça (2015) aponta que no caso das jovens mulheres "elas não têm direito à visita íntima e sabe que o companheiro tem direito" enquanto que no caso dos jovens homens "se o que eles querem não for atendido, logo eles "fazem barulho queimando colchões" (Conselho Nacional de Justiça 2015, p. 89). O mesmo relatório aponta que as jovens são proibidas de receber visita íntima, razão dentre as quais "perderam seus laços com antigos(as) companheiros(as)" (Conselho Nacional de Justiça 2015, p. 161). Ademais, também a educação sexual das jovens é ausente, o que implica não apenas na falta de diálogo e informação sobre métodos contraceptivos e prevenção de doenças sexualmente transmissíveis, mas, principalmente, o combate ao abuso e violência sexuais, visto que o relatório destaca que algumas adolescentes "falaram de abusos sexuais sofridos, uma pelo tio e outra pelo padrasto" (Conselho Nacional de Justiça 2015, p. 162).

Cabe ainda enfatizar que muitas adolescentes enquanto em cumprimento de medida de internação começam a desenvolver relacionamentos homoafetivos com suas colegas de unidade. Tal relacionamento é justificado, principalmentos pelos técnicos que trabalham no local, como resultado da carência e da solidão que as jovens vivem ali, encaradas 
como transitórias e restritas ao periodo de internação, não sendo compreendidas como uma relação "de verdade". Além disso, geralmente, essas relações são ignoradas ou mesmo proibidas nas unidades, acarretando, com frequência, práticas punitivas às adolescentes envolvidas. Essa negação da legitimidade da homoafetividade da relação entre as jovens produz efeitos importantes, não apenas no que diz respeito à limitação da experiência de suas sexualidades, mas impedindo também a possibilidade de abordalás em termos de políticas de saúde, prevenção de doenças sexualmente transmissíveis e na vida diária nas unidades.

Entretanto, é interessante apontar que muitas adolescentes internadas se apresentam como boys. Ou seja, essas jovens performatizam e buscam se mostrar "masculinizadas", seja na forma de vestir-se, seja na forma de comportar-se ou de gesticular (Conselho Nacional de Justiça 2015). A figura do boy é pertinente de se ressaltar - elas mesmas se chamam e identificam as colegas que se apresentam assim com essa nomenclatura -, pois marca uma diferenciação e forma de resistir ao contexto institucional em que estão inseridas, afirmando uma diferença no exercicio de suas sexualidades.

Um outro exemplo de violações de direitos durante o cumprimento do ato infracional, ainda que o documento em questão seja especificado para uma unidade de internação masculina, o relatório da Comissão de Direitos Humanos da Ordem dos Advogados do Brasil - OAB, Mato Grosso do Sul/Brasil, nos é útil aqui devido à perpetuação de uma lógica punitiva que também ocorre nas unidades femininas, como veremos a seguir. Tal documento elaborado em 2014, portanto, vinte quatro anos após a promulgação do ECA, oito anos após a elaboração dos guias aqui analisados e dois anos após a implementação da lei do Sinase (Lei no 12.594), indica as condições de uma Unei, evidenciando que "o estabelecimento 'educacional' na realidade é muito semelhante às Unidades Prisionais do Estado de Mato Grosso do Sul, exceto pela proibição da entrada de cigarros e dinheiro, bem como pelas diferenciações teóricas introduzidas pelo ECA" (Mato Grosso do Sul 2014). O relatório indica que - ainda que a Unei esteja interditada desde 2013 por decisão judicial e que até o presente momento não possua corpo técnico suficiente para o trabalho de socioeducação, visto que são apenas 10 profissionais, sendo necessário, entretanto, no mínimo 17 - o que há de fato é um funcionamento nos moldes prisionais. O ambulatório, inaugurado em 2009 para atender aos jovens, até a data da visita da $\mathrm{OAB}$, também não estava em funcionamento. $O$ relatório aponta que não há efetivo suficiente de professores para ministrar as aulas.

Destaca-se que "a estrutura precária, com excesso de ociosidade dentro das unidades, é um dos motivos mais evidentes para as constantes turbulências", além de afirmar que as mudanças de nomenclatura, onde "celas" são denominadas "alojamentos", "pavilhões" de "alas", "cela forte disciplinar" de "Centro de Reflexão", e "agentes" de "educadores", não resultam em qualquer diferença prática (Mato Grosso do Sul 2014). Ressaltamos que o modelo "Centro de Reflexão" está presente, também, na internação das jovens mulheres, contudo de uma forma diferente visto que "segundo a equipe técnica, o "local da reflexão" é no próprio quarto 'você vai ficar aí, refletindo, pensar um pouquinho na vida. Vai ficar quietinha, direitinha, para não piorar a situação'" (Conselho Nacional de Justiça 2015, pp. 89-90).

Salientamos, portanto, que o Estatuto da Criança e do Adolescente (ECA) conta com menos de 30 anos de existência, mas sua vigência não coincide exatamente com sua 
implementação, pois no que tange à população jovem em conflito com a lei, foram diversas as iniciativas realizadas através de Propostas de Emenda à Constituição - PEC desde 1993, três anos após sua promulgação, para a redução da maioridade penal no país. É nesse contexto que se deve levar em consideração a questão das práticas operacionalizadas, no presente, à infância e juventude estarem ainda carregadas das lógicas recrudescedoras dos antigos Códigos de Menores, em uma associação que articula não apenas crime e pobreza, mas que concerne a uma atribuição punitiva às medidas socioeducativas que corroboram para a não eficácia do ECA. Destacamos, especialmente o contexto brasileiro atual, que a lógica retrógrada e menorista avança com ainda mais força a partir da mudança da gestão no âmbito da presidência da república.

\section{Medida Socioeducativa em Meio Aberto: rede pessoal e projeto de vida}

Nesta parte do artigo entramos no segundo eixo de análise, que se dirige à condução geral das políticas de atendimento no sistema socioeducativo. Como parte do procedimento metodológico, analisamos o contexto das Unidades Educacionais de Internação - UNEIS (já discutidos acima) e passamos agora a discutir mais detidamente sobre algumas visitas feitas a um Centro de Referência Especializado de Assistência Social - CREAS. O objetivo desse percurso foi o contato com os profissionais ligados aos jovens durante o cumprimento da medida socioeducativa para compreender a maneira como a rede de atendimento se organizava no atendimento à essa população e, também, como as estratégias socioeducativas eram postas em prática na operacionalização da medida.

O CREAS é um estabelecimento da política pública de Assistência Social que oferta serviços de proteção e atendimento interdisciplinar a pessoas em situação de violação de direitos. Nesse estabelecimento há uma equipe responsável pelo acompanhamento das Medidas Socioeducativas em Meio Aberto. Essa equipe organiza parcerias com estabelecimentos públicos e privados para encaminhar as/os jovens aos locais nos quais será cumprida a medida, bem como avalia a/o jovem durante todo o tempo em que ele/a está em cumprimento de uma medida socioeducativa em meio aberto, onde o acompanhamento se estende à família da/o jovem, pela realização de um diagnóstico psicossocial feito através de visitas domiciliares e reuniões no próprio estabelecimento. Contudo, mais uma vez, apesar das visitas não terem sido restritas ao contexto das meninas em cumprimento de medida no meio aberto, notamos a preponderância de práticas e mesmo das próprias políticas serem voltadas para atender os jovens do sexo masculino. Dessa forma, tanto o modelo do atendimento socioeducativo de internação quanto do em meio aberto estão voltados para focar nas demandas dos adolescentes homens.

Neste momento, gostaríamos de apresentar um ponto que, ainda que não se relacione diretamente à questão de gênero que temos apontado para a discussão neste artigo, torna-se relevante por incidir diretamente no modo pelo qual o direcionamento, $\mathrm{o}$ encaminhamento e a própria gestão do cotidiano do cumprimento das medidas em meio aberto se dirigem à população juvenil de um modo geral.

Durante o período em que acompanhamos o trabalho da equipe responsável pelas Medidas Socioeducativas em meio aberto, uma questão que se apresentou como um 
analisador da rede de atenção foi o termo rede pessoal. A rede pessoal facilitava a entrada da jovem nos estabelecimentos para que ela pudesse cumprir a medida; essa rede se constituía por uma relação entre o técnico de referência do CREAS responsável pelo acompanhamento das Medidas Socioeducativas, de modo que o estabelecimento que receberia a jovem estaria fazendo um favor ao CREAS e, especialmente, à jovem. Essa rede pessoal, em nossa análise, indica uma relação com o serviço prestado que não é da ordem do direito, mas de favor e a Assistência Social é operacionalizada, dessa forma, de maneira assistencialista, pois para que a jovem possa ser atendida, cabe ao profissional que a acompanha ter um bom relacionamento pessoal com os outros profissionais da rede, caso contrário, o acesso aos serviços que a jovem deveria receber pode ser dificultado. Ou seja, o acesso ao direito pela juventude não depende unicamente da lei, mas da composição de uma rede de relações interpessoais que ocorrem por vias informais.

Esse contexto de informalidade que atravessa o atendimento se complica, especialmente, quando nessa rede de atendimento misturam-se profissionais concursados (ocupando cargos permanentes) e outros que ocupam cargos de confiança devido às filiações partidárias (ocupando cargos provisórios vinculados às eleições). Essa vinculação trabalhista é importante de considerar porque modulam também o encaminhamento (ou a falta dele) da população jovem aos serviços. Devido a projetos políticos partidários distintos, questões pessoais dos técnicos interferem diretamente nos possíveis modos de tratamento da juventude. Um exemplo disso é quando encontramos funcionários que desenvolvem certos projetos que com o tempo são extintos, pois não podem prosseguir em uma continuidade devido à mudança de gestão; ou devido à convicções religiosas que atravessam determinados partidos políticos e que estão presentes nas atividades propostas pelos técnicos a eles vinculados, delineando fatores da ordem de uma crença como balizadores do atendimento dos jovens.

Foi no CREAS que pudemos ter contato com o governo da juventude em conflito com a lei por certos dispositivos, subsidiados por saberes como a psicologia, a psiquiatria e o direito. Um desses dispositivos é o Plano Individual de Atendimento - PIA e também algo que era desenvolvido de modo arbitrário e paralelo ao PIA, que o psicólogo da equipe técnica denominou de Projeto de Vida. O PIA é um instrumento previsto no SINASE (Lei no 12.594) e que tem como função "previsão, registro e gestão das atividades a serem desenvolvidas com o adolescente" (Lei no 12.594), esse instrumento deveria ser construído juntamente com a/o jovem e ter a participação dos seus responsáveis, pensando "o programa de atendimento mais adequado para o cumprimento da medida" (Lei $n^{0}$ 12.594). O projeto de vida é um plano de atendimento que os técnicos do CREAS do município têm adotado como objetivo de tratamento da/o jovem.

De um modo geral, a operacionalização do encaminhamento das/dos jovens acaba por não ser baseada nas prescritivas do SINASE, pois o que de fato acontece é a equipe técnica designar o programa mais adequado - nesse caso, dependendo dos contatos realizados pela rede pessoal. Outra questão que se sobrepõe a essa rede pessoal para o sucesso ou insucesso dos encaminhamentos reside no tipo de delito cometido pela/o jovem. Segundo nos informou o psicólogo responsável, as/os jovens que cometem infração devido ao tráfico de drogas, por exemplo, não são aceitos em escolas para o cumprimento da medida, pois estariam em contato com crianças - o que dá visibilidade 
ao fato de que, dependendo do tipo de infração cometida, a/o jovem é impedido de se inserir em um determinado espaço pelo perigo que representa, ainda que a legislação, em tese, "garanta" o acesso da/o jovem à escola.

Paralelamente ao PIA, o psicólogo responsável pelas Medidas Socioeducativas afirmou que a equipe busca fazer a/o jovem pensar sobre um Projeto de Vida, ressaltando que essa é uma estratégia não prevista pelo SINASE (Lei no 12.594) e cujo objetivo é fazer com que a/o jovem pense em um futuro melhor e faça com que ele consiga "sair do mundo das drogas" e "arrumar um trabalho". O trabalho é um tema que aparece também em outros momentos da pesquisa em que acompanhamos audiências na Vara da Infância e Juventude. Uma das primeiras perguntas feitas aos jovens é se trabalham, se estudam, o que fazem da vida. A necessidade de ser, não somente um sujeito útil, mas alguém que ocupa o tempo em um exercício produtivo é um dos efeitos de uma sociedade que é regida por uma lógica econômica, tanto no sentido de produção, mas, também e, principalmente, econômica no sentido de gestão (Foucault 2008a, 2008b). Essa forma de gerir a população jovem faz parte do conjunto de práticas que articulam saber e poder que produzem a cisão entre o sujeito vagabundo e o sujeito útil; considerando que no caso do primeiro, é preciso torná-lo útil através de uma série de exercícios, as Medidas Socioeducativas são um exemplo de um desses exercícios.

O interessante nesses procedimentos que buscam a constituição de um sujeito útil é que não se trata de um exercício no qual se possibilitará que o sujeito tenha acesso a outras possibilidades de existência, mas um exercício de transformação interior desse sujeito. É preciso que ele obedeça e que admita, falando sobre si, uma mudança para melhor: "um futuro melhor", "sair das drogas", "arrumar um trabalho". Todas essas estratégias se utilizam de uma tecnologia disciplinar que individualiza as questões socioeconômicas nas quais essa/esse jovem está inserido/a, pois, atribui unicamente a/o jovem a responsabilidade por poder modificar a si mesmo através de uma adequação/adaptação comportamental.

Outra questão fundamental é que nem sempre a/o jovem decide exatamente sobre o seu próprio Projeto de Vida, já que a questão de estudar ou de "sair do mundo das drogas" não é exatamente trabalhado com a/o jovem, mas imposto a ela/ele. Não abordamos essa questão para culpabilizar o profissional que faz o atendimento dessa população, mesmo porque muitas vezes a equipe técnica também está sobrecarregada com inúmeras outras atividades, geralmente relacionadas à elaboração de pareceres a serem adensados aos processos judiciais dessa população. No entanto, mesmo quando essas questões são discutidas com a/o jovem, o atrelamento da viabilidade de execução desse projeto esbarra na rede pessoal. Por um lado, a rede pessoal poderia fomentar a parceria entre serviços, arranjando alternativas para realização das combinações; por outro, um dos entraves, é quando os técnicos dos serviços possuem algum tipo de desavença, pois essa informalidade é o principal componente, como salienta a fala do psicólogo, para o funcionamento da rede e a viabilidade de atendimento efetivo à juventude.

\subsection{No império da lei quem tem projeto de vida é sujeito de direito}

No ano de 2006 foram distribuídos pela Secretaria Especial dos Direitos Humanos da Presidência da República três guias, sendo eles intitulados: Por uma política nacional de execução das medidas socioeducativas: conceitos e princípios norteadores, Os Regimes 
de Atendimento no Estatuto da Criança e do Adolescente: Perspectivas e Desafios e Socioeducação: estrutura e funcionamento da Comunidade Educativa.

A importância de se discutir o conteúdo dos guias se faz em razão de que, mesmo com a implementação do SINASE (Lei n⿳0 12.594), os pressupostos contidos nos guias ainda fundamentam as práticas dos técnicos que atuam com a população juvenil que cumpre medidas socioeducativas, indicando a prevalência da racionalidade dos códigos de menores anteriores ao ECA. Além disso, o próprio documento afirma que o objetivo das publicações é "o fortalecimento da garantia dos direitos fundamentais das (os) adolescentes em conflito com a lei" justificado pelo fato de que ainda no presente "se observa a dicotomia entre os novos marcos legais conceituais que propugnam pela socioeducação e as velhas práticas tutelares opressoras" (Secretaria Especial dos Direitos Humanos 2006a, p. 5). No entanto, encontramos um paradoxo, pois os mesmos guias que buscam fortalecer a garantia dos direitos da população juvenil, são constituídos por discursos que violam os direitos que supostamente visam garantir!

O guia Por uma política nacional de execução das medidas socioeducativas: conceitos e princípios norteadores ao abordar "o delito juvenil na sociedade contemporânea e os itinerários de exclusão a que estão expostos os adolescentes" (Secretaria Especial dos Direitos Humanos 2006c, p. 5) refere que a questão do delito juvenil deve ser pensada não em função do número de incidência em infrações, mas em função da complexidade. Isso é importante de sinalizar, pois o número de jovens que cumprem medidas socioeducativas no país é relativamente reduzido quando comparado à criminalidade adulta. Ressalta ainda que as "repercussões sociais e a inoperância ou a atuação equivocada do Estado no seu enfrentamento, no entanto, têm levado a uma percepção distorcida de sua real magnitude" (Secretaria Especial dos Direitos Humanos 2006b, p. 9).

Diversos termos utilizados nesse documento, tais como vulnerabilidade, fragilidade da família, construção da identidade e "viabilização enquanto pessoa", não são definidos, o que torna difícil o entendimento do campo teórico do qual parte a elaboração do guia. Um exemplo ainda mais confuso é o "plasmar a identidade". No contexto do guia, "plasmar a identidade" é estabelecido como uma questão fundamental com a qual uma pessoa se defronta no período da adolescência, assim como é nessa época que esse sujeito deve "forjar seu projeto de vida" (Secretaria Especial dos Direitos Humanos 2006b, p. 22). Aqui podemos ver como a prática do psicólogo do CREAS mencionado anteriormente, se sustenta, pois é fundamentada por saberes que colocam a adolescência como um período no qual existe uma procura do sujeito por sua identidade, um momento de confusão no qual, como aparece no guia, "o jovem se procura e se experimenta, se confunde e, algumas vezes, se perde" (Secretaria Especial dos Direitos Humanos 2006b, p. 22).

O momento em que a juventude se perde seria aquele no qual comete o ato infracional. O discurso de saber colocado em prática no guia abre um espaço em que se naturaliza o ato infracional como algo comum à fase adolescente, mas não apenas isso: ao naturalizar individualiza a questão, excluindo outros determinantes tais como o não acesso a uma política educacional, de saúde, e uma série de violações de direitos que se fazem presentes anteriormente ao ato infracional como é o caso da evasão escolar, inserção informal no campo do trabalho, dependência química, abuso e violência sexual, e do próprio exercício da sexualidade, como apresentado anteriormente neste texto. Esse 
contexto de violações nos leva a refletir que não apenas houve um abandono da/do jovem em relação à escola, por exemplo, mas a/o próprio jovem foi mantida/o fora da política. A política é proposta para uma categoria populacional, essa categoria é caracterizada a partir de uma produção de diversos discursos acerca dessa população, contudo a intervenção se dá no corpo individual e exige-se do sujeito uma relação consigo mesmo, o que demanda dele um ideal. Não importa, portanto, a singularidade do sujeito, mas é preciso ser o sujeito daquele direito: isto é, as políticas públicas demandam, assim como todas as tecnologias de poder que incidem sobre o corpo, a produção de uma subjetividade.

No guia Os regimes de atendimento no Estatuto da Criança e do Adolescente: perspectivas e desafio, uma das propostas é que os programas socioeducativos fossem executados em uma lógica de educação comunitária. Essa lógica seria complementar às ações junto à família e à escola, para que o desenvolvimento pessoal, social e profissional de crianças e adolescentes fossem implantadas em espaço situado fora da família e da escola, portanto, tomando tais espaços como isolados do que o guia considera enquanto comunidade. Apesar de o guia apontar a situação atual da operacionalização das medidas socioeducativas enquanto ainda marcadas por uma lógica que toma a/o adolescente como potencial delinquente, assim como a presença de práticas assistencialistas, a proposta de ênfase técnico/instrumental demarcada como princípio de trabalho com a juventude em conflito com a lei somada à educação comunitária que, aliás, não é sequer definida ou contextualizada, apenas contribui para a manutenção do paradigma que o próprio guia faz crítica.

Dentre as orientações contidas no guia está a de que a aplicação da medida socioeducativa deve ser operada de maneira severa e rigorosa "para que o adolescente sinta que, sobre ele, não está sendo exercido um controle tênue e ineficaz". Afirma-se, ainda, que a dimensão socioeducativa deve se basear na humanidade, severidade e justiça, cujo objetivo é fazer com que o adolescente tenha "consciência muito clara de que a sociedade, com base na lei, está-lhe impondo uma nova forma de vida, como resposta ao ato infracional por ele cometido" (Secretaria Especial dos Direitos Humanos 2006a, p. 60). A nova forma de vida que é imposta implica não a mudança das condições nas quais a/o jovem vive, mas uma transformação interna da/o própria/o jovem, como se a constituição de uma subjetividade estivesse descolada do contexto social no qual se está inserido. Dizer isso não significa atualizar as ideias de Enrico Ferri sobre as condições econômicas e sociais produzirem criminosos, atrelando pobreza e crime, ao contrário: ao afirmarmos que a subjetividade é produzida no contato com esse contexto social, possibilitamos a problematização das condições nas quais a/o jovem vive, de modo que a questão não é uma transformação da/o jovem, mas do próprio contexto em que ela/ele vive - o que não raro denuncia as violações de direitos.

A humanidade preconizada na cartilha corresponde "à aplicação rigorosa dos direitos e garantia dos internos" (Secretaria Especial dos Direitos Humanos 2006a, p. 69) previstos pela Constituição Federal, pelo ECA e nas legislações complementares, mas isso a partir de um trabalho que deve ser desenvolvido com a/o jovem. É o infrator que deve ser transformado, é a infratora que deve ser modificada. Retomando a prática da equipe que acompanha as medidas socioeducativas no CREAS, pode-se visibilizar como a questão dos direitos dos jovens se desloca para uma esfera de favores entre profissionais, além 
de incidir sobre a/o jovem que deverá adequar seu comportamento, mesmo que essa adequação se constitua por saber qual a resposta correta a dar para uma determinada pergunta como, por exemplo, sobre o uso de drogas.

A severidade compreendida na "reprovação social, não do adolescente, mas do ato por ele cometido" (Secretaria Especial dos Direitos Humanos 2006a, p. 69) nos faz pensar que é através do cumprimento daquilo que é imposto pelos educadores que a severidade é operada, a partir de um "processo de educação para valores que, pela significação e ressignificação do significado e do sentido da vida" (Secretaria Especial dos Direitos Humanos 2006a, p. 69) que leve a/o jovem a se conscientizar sobre as implicações e gravidade do ato infracional, mas não ao delito tão somente, como ao modo como têm se comportado em geral. Ou seja, a severidade, como estabelecida pelo guia, atrela moralização e penalidade possibilitando que não apenas a infração seja o foco do processo de educação, mas abrindo espaço para que o próprio sujeito seja passível de correção.

A coerção é aquilo que estabelece um nexo entre moral e penalidade. É aquilo que tem por alvo não apenas as infrações dos indivíduos, mas a natureza e o caráter deles. É aquilo que deve ter como instrumento uma vigilância permanente e fundamental. (Foucault 2015, p. 103)

Por fim, a justiça é enfatizada pela "defesa intransigente da aplicação das leis. O sistema de atendimento deve funcionar sob um forte e rigoroso império da lei" (Secretaria Especial dos Direitos Humanos 2006a, p. 69). No início do presente texto mencionamos que em uma mesma categoria existem diferentes modos de operacionalizar os direitos dispostos no Estatuto da Criança e do Adolescente (Lei no 8.069). Se por um lado as crianças e adolescentes que têm seus direitos violados entram no sistema de justiça através de medidas protetivas, por outro, os jovens que cometem ato infracional são capturados pela via da socioeducação (Scisleski et al. 2015a). O funcionamento do sistema socioeducativo sob o denominado império da lei, como preconizado pelos guias, é bastante seletivo no que diz respeito à intransigente aplicação das leis. Partindo do PIA, onde estabelece o SINASE:

Art. 52. O cumprimento das medidas socioeducativas, em regime de prestação de serviços à comunidade, liberdade assistida, semiliberdade ou internação, dependerá de Plano Individual de Atendimento (PIA), instrumento de previsão, registro e gestão das atividades a serem desenvolvidas com o adolescente. (Conselho Nacional de Justiça 2012)

Questionamos: como pode uma medida socioeducativa ser operacionalizada respeitando todos os direitos estabelecidos em lei aos jovens, se o instrumento que é responsável pelo planejamento, gestão e registro das atividades não é cumprido? Segundo dados do Sistema Nacional de Justiça "somente 5\% dos processos se tem informação acerca da aplicação do PIA para os adolescentes a que se referem os processos analisados, sendo que em $77 \%$ dos processos se tem certeza de que não há tal plano" (Conselho Nacional de Justiça 2012, p. 31). Ressalta-se, ainda, a operacionalização de um acompanhamento arbitrário através do Projeto de vida e da rede pessoal estabelecida entre os profissionais da rede de atendimento socioeducativo.

Outra questão diz respeito aos Direitos Processuais, onde em relação à ocorrência de intimação e questionamento sobre o desejo de recorrer à defesa nos processos de internação definitiva, o relatório do Sistema Nacional de Justiça indica que em “66\% dos 
autos analisados não consta esta informação; ou seja, não se registra nos autos a formalização ou não de um ato que é um direito fundamental do adolescente e cuja não realização pode caracterizar cerceamento do direito de defesa" (Conselho Nacional de Justiça 2012, p. 33). De modo que se pode afirmar que a lei tem sido operacionalizada a partir de uma cisão entre aqueles sujeitos aos quais se protegerá e aqueles aos quais é a punição a palavra de ordem, mesmo em se tratando de uma população que, em cumprimento de medida socioeducativa, está sob a Doutrina da Proteção Integral.

O guia sobre Socioeducação: estrutura e funcionamento da Comunidade Educativa se constitui enquanto uma proposta de orientação teórico-prática à equipe dirigente e técnica das unidades de internação. A proposta do guia é a de que a socioeducação seja operacionalizada em conjunto com a educação básica e profissional, com objetivos como: respeito à integridade dos jovens privados de liberdade, desenvolvimento de ação socioeducativa de qualidade "visando formar o adolescente como pessoa, cidadão e futuro profissional" e "a segurança dos cidadãos, pela efetiva redução dos atos infracionais cometidos por adolescentes" (Secretaria Especial dos Direitos Humanos 2006c, p. 10).

A juventude em conflito com a lei, é constituída, então, como aquela que oferece perigo à sociedade, de modo que devem ser criadas estratégias de segurança para que a sociedade seja protegida. Algumas dessas estratégias são visíveis nas práticas dos profissionais que atuam junto às medidas como na produção de um projeto de vida, na qual se busca fazer com que esse sujeito jovem seja útil e produtivo, e em decisões judiciais, em que pelo fato do jovem oferecer perigo a si mesmo e aos demais serve como fundamento legal para ser encaminhado à internação. Nas Unidades Educacionais de Internação - as UNEIs - em Campo Grande/MS não se disponibilizam preservativos aos jovens para evitar a contaminação de doenças, mas a primeira providência a ser tomada é raspar o cabelo dos meninos para evitar que haja proliferação de piolhos. Da mesma maneira, a orientação sexual das meninas, quando homoafetiva, busca ser combatida e não reconhecida como relação legítima, o que impede não apenas o exercício sexual dessas jovens, como também o impedimento em se pensar na prevenção e no combate a doenças sexualmente transmissiveis, etc.

O guia afirma que a educação é o único processo capaz de transformar o potencial das pessoas em competências, capacidades e habilidades, sendo a saúde, alimentação, dignidade, respeito, integridade física, psicológica e moral as condições para a ação educativa (Secretaria Especial dos Direitos Humanos 2006c, p. 55). Entretanto, afirma logo em seguida que "muito mais importante que alimentação, lugar para dormir, roupa, matrícula na escola, etc., esse educando precisa que suas necessidades de estima sejam satisfeitas, isto é, precisa sentir-se compreendido e aceito", pois, quem não se sente compreendido e aceito por pelo menos uma pessoa, neste mundo, pode tornar-se um perigo para si mesmo e para os outros (Secretaria Especial dos Direitos Humanos 2006c, p. 56). E ainda: "vista a situação por esse ângulo, os aspectos sociais subordinam-se à perspectiva do equacionamento da problemática pessoal do educando a quem dirigimos nosso trabalho social e educativo" (Secretaria Especial dos Direitos Humanos 2006c, p. 57).

Partindo dos pressupostos dos guias, é possível compreender que o que possibilita o estabelecimento de redes de favores entre profissionais, a não implementação do Plano 
Individual de Atendimento (Lei $\mathrm{n}^{\mathbf{0}}$ 12.594), além da operacionalização de um projeto de vida de cunho moralizador e, também, toda uma estruturação do sistema de atendimento não se dá pelos estabelecimentos da Assistência Social, mas pela via da Segurança Pública. A socioeducação é tomada como o dispositivo que deve exercer ação edificante na vida dessa juventude, e mais: a/o jovem é tomado, a priori, como alguém que, diante de inúmeras oportunidades, demonstra "apatia, indiferença, agressividade e outras reações, sentimentos e comportamentos destrutivos" (Secretaria Especial dos Direitos Humanos 2006c, p. 58). Ação edificante que deve ter por princípio construir e moldar um sujeito de modo que ele não ofereça mais perigo.

\section{Considerações Finais}

Este artigo discutiu, a partir de dois eixos de análise, o rumo pelos quais tem se direcionado as políticas de atendimento da população juvenil em conflito com a lei. Em um primeiro momento, priorizou-se debater o cenário das jovens que cumprem medida de internação a partir de uma análise de como as mesmas têm sido tratadas nas unidades. Em um segundo eixo analítico, apresentamos o panorama do atendimento da população jovem a partir das diretrizes que regem as próprias políticas de um modo geral, incluindo aqui o cenário do cumprimento da medida em meio-aberto.

No que diz respeito especialmente às questões de gênero que perpassam não apenas o cometimento do ato infracional das adolescentes mulheres, mas na operacionalização das medidas socioeducativas, é possível visibilizar que existe uma lógica de submissão e estereótipo das jovens não apenas no cometimento do ato infracional, como podemos identificar com relação à violação dos direitos de visita íntima, na interdição das relações homoafetivas e a ênfase dada à condição de gestante e de mães enquanto jovens. Além disso, as violações de direitos estão presentes anteriormente e durante o cumprimento da medida o que pode ser visibilizado pela ausência de dados nos Planos Individuais de Atendimento, defasagem escolar e repressão do exercicio da sexualidade das meninas.

Evidenciam-se, de um modo geral, a partir da configuração do sistema que atende aos jovens em regime cumprimento de medida socioeducativa, práticas punitivas e ilegais. Nesse aspecto, a operacionalização das políticas públicas para a juventude indica a execução de medidas que, subsidiadas por discursos produzidos na relação entre as instituições da saúde e da justiça, violam os direitos garantidos em lei.

É no contexto de proteção e violação que buscamos refletir sobre a vida e o que se tem tomado por direitos da juventude a partir do campo das políticas públicas, especialmente no que se refere à população jovem autora de infrações. Faz-se necessário problematizar não apenas a prática dos profissionais que atuam nas políticas públicas para jovens em conflito com a lei, mas os próprios saberes que subsidiam tais práticas. Ressaltando que não há uma dicotomia entre teoria e prática, pois uma prática só é possível em razão de um discurso que produz um determinado tipo de saber. Assim, no cenário atual, entendemos que é hora de lutar pelas garantias de direitos que já existem legalmente, mas que ainda estão longe de serem cumpridas.

\section{Referências}

Agamben, G., 2009. O que é o dispositivo?. Em: G. Agamben, O que é o contemporâneo? E outros ensaios. Trad.: V.N. Honesko. Chapecó: Argos, 25-54. 
Athayde, C., Bill, M.V., e Soares, L.E., 2005. Cabeça de porco. São Paulo: Objetiva.

Caetano, C.C., Scisleski, A.C.C., e Galeano, G.B., 2019. El investigador como testigo de la vida de la juventud infame. Athenea digital [em linha], 19(1), e2193. Disponível em: https://doi.org/10.5565/rev/athenea.2193 [Acessado em 26 de fevereiro de 2019].

Conselho Nacional de Justiça, 2012. Panorama Nacional - A Execução das Medidas Socioeducativas de Internação. Programa Justiça ao Jovem [em linha]. Brasília: CNJ. Disponível em: http://www.cnj.jus.br/images/pesquisasjudiciarias/Publicacoes/panorama nacional doj web.pdf [Acessado em 22 de abril de 2018].

Conselho Nacional de Justiça, 2015. Dos espaços aos direitos: a realidade da ressocialização na aplicação das medidas socioeducativas de internação das adolescentes do sexo feminino em conflito com a lei nas cinco regiões [em linha]. Coord. Marília Montenegro Pessoa de Mello; pesquisadores Camila Arruda Vidal Bastos et al. Brasília: CNJ.

Disponível em:

http://www.cnj.jus.br/files/conteudo/destaques/arquivo/2015/06/cb905d37b1c494f 05afc1a14ed56d96b.pdf [Acessado em 22 de abril de 2018].

Cunda, M., e Silva, R.N.A., 2014. O crack em um cenário empedrado: articulações entre os discursos jurídico, médico e midiático. Psicologia \& Sociedade [em linha, 26(n. spe.), 245-255. Disponível em: https://doi.org/10.1590/S0102-71822014000500025 [Acessado em 5 de setembro de 2019].

Foucault, M., 1979. Microfísica do poder. Rio de Janeiro: Graal.

Foucault, M., 1988. A História da sexualidade I: A vontade de saber. Trans.: M.T.D.C. Albuquerque e J.A.G. Albuquerque. Rio de Janeiro: Graal.

Foucault, M., 1996. A ordem do discurso. São Paulo: Loyola.

Foucault, M., 2005. Em defesa da sociedade. Trad.: M.E. Galvão. São Paulo: Martins Fontes.

Foucault, M., 2008a. Nascimento da biopolítica. Trans.: E. Brandão. São Paulo: Martins Fontes.

Foucault, M., 2008b. Segurança, territorio, população. Trans.: E. Brandão. São Paulo: Martins Fontes.

Foucault, M., 2015. A sociedade punitiva. São Paulo: WMF Martins Fontes.

Mato Grosso do Sul, 2014. OF.CIRC/CDH/OAB/MS/N.o02/2014 de 09 de abril de 2014. Relatório da Comissão Permanente de Direitos Humanos. Ordem dos Advogados do Brasil. Seção de Mato Grosso do Sul.

Scisleski, A.C.C., 2006. Entre se quiser, saia se puder: os percursos dos jovens pelas redes sociais. Dissertação de Mestrado, Psicologia Social e Institucional. Porto Alegre: Universidade Federal do Rio Grande do Sul.

Scisleski, A.C.C., et al., 2014. Medida Socioeducativa de Internação: dos corpos dóceis às vidas nuas. Psicologia: Ciência e Profissão [em linha], 34(3), 660-675. Disponível 
em: https://doi.org/10.1590/1982-3703001682013 [Acessado em 22 de abril de 2018].

Scisleski, A.C.C., et al., 2015a. Life in the Logic of Exception: Violation of Rights and Abandonment. International Journal Advances in Social Science and Humanities [em linha], 3(8), 18-26. Disponível em:

http://www.ijassh.com/index.php/I]ASSH/article/view/163 [Acessado em 5 de setembro de 2019].

Scisleski, A.C.C., et al., 2015b. Medida socioeducativa de internação: estratégia punitiva ou protetiva?. Psicologia \& Sociedade [em linha], 27(3), 505-515. Disponível em: https://doi.org/10.1590/1807-03102015v27n3p505 [Acessado em 22 de abril de 2018].

Scisleski, A.C.C., et al., 2017. A lei em conflito com o jovem: problematizando as políticas públicas. Polis e Psique [em linha], 7(2), 4-27. Disponível em.

https://doi.org/10.22456/2238-152X.70477 [Acessado em 22 de abril de 2018].

Secretaria Especial dos Direitos Humanos, 2006a. Os Regimes de Atendimento no Estatuto da Criança e do Adolescente: Perspectivas e Desafios [em linha]. Coordenação técnica: Antônio Carlos Gomes da Costa. Brasília: Ministério da Justiça. Disponível em: http://ens.sinase.sdh.gov.br/ens2/images/Biblioteca/Livros_e_Artigos/material_cu rso de formacao da ens/Os $\% 20$ Regimes $\% 20 \mathrm{de} \% 20$ Atendimemto $\% 20$ no $\% 20$ Esta tuto $\% 20 \mathrm{da} \% 20 \mathrm{Crian} \% \mathrm{C} 3 \% \mathrm{~A} 7 \mathrm{a} \% 20 \mathrm{e} \% 20 \mathrm{do} \% 20$ Adolescente.pdf [Acessado em 5 de setembro de 2019].

Secretaria Especial dos Direitos Humanos, 2006b. Por uma política nacional de execução das medidas socioeducativas: conceitos e princípios norteadores [em linha].

Coordenação técnica: Antônio Carlos Gomes da Costa. Brasília: Ministério da Justiça. Disponível em:

http://ens.sinase.sdh.gov.br/ens2/images/Biblioteca/Livros_e_Artigos/material_cu rso de formacao da ens/Por $\% 20$ uma $\% 20 \mathrm{Pol} \% \mathrm{C} 3 \%$ ADca $\% 20$ Nacional $\% 20 \mathrm{de} \% 20$ Execu\%C3\%A7\%C3\%A30\%20das\%20Medidas\%20Socioeducativas.pdf [Acessado em 5 de setembro de 2019].

Secretaria Especial dos Direitos Humanos, 2006c. Socioeducação: Estrutura e Funcionamento da Comunidade Educativa [em linha]. Coordenação técnica: Antônio Carlos Gomes da Costa. Brasília: Ministério da Justiça. Disponível em: http://ens.sinase.sdh.gov.br/ens2/images/Biblioteca/Livros e Artigos/material cu rso de formacao da ens/Socioeducacao.pdf [Acessado em 5 de setembro de 2019].

Silva, R.N., 2004. Notas para uma genealogia da Psicologia Social. Psicologia E Sociedade [em linha], 16(2), 12-19. Disponível em: https://doi.org/10.1590/S0102$\underline{71822004000200003}$ [Acessado em 5 de setembro de 2019].

Trevisani, T.M., 2013. Camisa de força para menores: a patologização de crianças e adolescentes (Hospício São Pedro, 1884-1929). Dissertação de Mestrado. Psicologia Social e Institucional. Porto Alegre: Universidade Federal do Rio Grande do Sul.

Vicentin, M.C.G., 2005. A vida em rebelião: jovens em conflito com a lei. São Paulo: Hucitec. 


\section{Referências normativas}

Decreto no 17.943 de 12 de outubro de 1927. Consolida as leis de assistência e proteção a menores. Diário Oficial da União [em linha]. Disponível em:

http://www.planalto.gov.br/ccivil 03/decreto/1910-1929/d17943a.htm [Acessado em 22 de abril de 2018].

Lei no 6.697 de 10 de outubro de 1979. Institui o Código de Menores. Diário Oficial da União [em linha]. Disponível em: http://www.planalto.gov.br/ccivil 03/leis/19701979/16697.htm [Acessado em 22 de abril de 2018].

Lei no 8.069, de 13 de julho de 1990. Dispõe sobre o Estatuto da Criança e do Adolescente e dá outras providências. Diário Oficial da União [em linha], 16 de julho. Disponível em: http://www.planalto.gov.br/ccivil 03/Leis/L8069.htm [Acessado em 14 de agosto de 2017].

Lei no 12.594 de 18 de janeiro de 2012. Institui o Sistema Nacional de Atendimento Socioeducativo (SINASE), regulamenta a execução das medidas socioeducativas destinadas a adolescente que pratique ato infracional. Diário Oficial da União [em linha]. Disponível em: http://www.planalto.gov.br/ccivil 03/ ato20112014/2012/lei/112594.htm [Acessado em 22 de abril 2018]. 